\title{
Oralidad terciaria: mirada ecológica a la radio digital
}

\section{Adriana Ángel-Botero ${ }^{1}$ Carlos Fernando Alvarado-Duque ${ }^{2}$}

Recibido: 2015-08-06

Enviado a pares: 2015-08-06

DOI: 10.5294/pacla.2016.19.2.6
Aprobado por pares: 2015-09-07

Aceptado: 2015-09-15

Para citar este artículo / To reference this article / Para citar este artigo

Ángel-Botero, A. \& Alvarado-Duque, C. A. (Junio de 2016). Oralidad terciaria: mirada ecológica a la radio digital. Palabra Clave, 19(2), 473-500. DOI: 10.5294/pacla.2016.19.2.6

\section{Resumen}

El crecimiento y la apropiación acelerados de las nuevas tecnologías (telefonía móvil, tabletas, computadores personales) han generado una reconfiguración mediática de la radio, lo cual, a su vez, ha redefinido un nuevo hábitat de escucha radial basado en la oralidad terciaria. De esta manera, y partiendo de los planteamientos hechos por Ong sobre la oralidad secundaria como modo de conciencia, este estudio analiza la manera como la oralidad terciaria se constituye como tecnología de pensamiento que cambia la experiencia de escucha de la radio en plataformas web. Retomando estudios fenomenológicos previamente realizados en la tradición del campo del media ecology, la presente investigación se sustenta en un estudio fenomenológico basado en entrevistas a oyentes de radio digital. Estas entrevistas fueron estructuradas según los cuatro existencialismos propuestos por Van Manen: espacialidad, temporalidad, relacionalidad y corporalidad. A partir del análisis de estos existencialismos, se proponen tres características de la oralidad terciaria, como la vivacidad, la transcodificación y la adresividad.

\section{Palabras clave}

Radio digital; oralidad terciaria; fenomenología; media ecology; existencialismos (Fuente: Tesauro de la Unesco).

\footnotetext{
Universidad de Manizales. Colombia. aangel@umanizales.edu.co

2 Universidad de Manizales. Colombia. cfalvarado@umanizales.edu.co
} 


\section{Tertiary Orality: An Organic Look to Digital Radio}

\section{Abstract}

The growth and rapid appropriation of new technologies (mobile telephones, tablets, and personal computers) have generated a reconfiguration of radio media, which, in turn, has redefined a new habitat-based radio listening tertiary orality. Thus, and based on the proposals raised by Ong on secondary orality as a mode of consciousness, this study analyzes the way the tertiary orality is established as technology thought changing experience of listening to the radio web platforms. Returning to previous studies phenomenological tradition in the field of media ecology, this research is based on a phenomenological study based on interviews with digital radio listeners. These interviews were structured according to the four existentialism proposed by Van Manen: spatiality, temporality, relationality and corporality. From the analysis of these existentialism, three characteristics of tertiary orality such as liveliness, transcoding and aggressiveness are proposed.

\section{Keywords}

Digital radio; tertiary orality; phenomenology; media ecology; existentialism (Source: Unesco Thesaurus). 


\section{Oralidade terciária: olhar ecológico na rádio digital}

\section{Resumo}

O crescimento e a apropriação acelerados das novas tecnologias (telefonia móvel, tablets, computadores pessoais) vêm gerando uma reconfiguração midiática da rádio, o que, por sua vez, redefine um novo habitat de escuta radial baseado na oralidade terciária. Dessa maneira e partindo das proposições feitas por Ong sobre a oralidade secundária como modo de consciência, este estudo analisa a maneira como a oralidade terciária se constitui como tecnologia de pensamento que muda a experiência de escuta da rádio em plataformas web. Retomando estudos fenomenológicos previamente realizados na tradição do campo da media ecology, esta pesquisa se fundamenta num estudo fenomenológico baseado em entrevistas a ouvintes de rádio digital. Essas entrevistas foram estruturadas segundo os quatro existencialismos apresentados por Van Manen: espacialidade, temporalidade, relacionalidade e corporalidade. A partir da análise desses existencialismos, propõe-se três características da oralidade terciária, como a vivacidade, a transcodificação e a adressividade.

\section{Palavras-chave}

Rádio digital; oralidade terciária; fenomenologia; media ecology; existencialismos (Fonte: Tesauro da Unesco). 


\section{Introducción}

Desde su llegada al país, la radio ha desempeñado un papel fundamental en la sociedad colombiana. Además de ser el segundo medio de comunicación más consumido después de la televisión (Mapa de Medios, 2015), la radio ha generado procesos sociales, políticos y culturales que han tenido una incidencia significativa en la historia del país (Castellanos, 2001; El'Gazi, 2011; Lalinde, 1998). El crecimiento y la apropiación acelerados de las nuevas tecnologías (telefonía móvil, tabletas, computadores personales) han generado una reconfiguración mediática de la radio, lo cual, a su vez, ha redefinido un nuevo hábitat de escucha radial basado en la oralidad terciaria (Logan, 2010). Un estudio reciente realizado por el Ministerio de Tecnologías de la Información y las Comunicaciones (MinTIC, 2013) afirma que $40 \%$ de los colombianos escucha radio a través de su celular. De esta manera, internet se ha convertido en una plataforma central de operación de la radio, que les permite a las emisoras no solo transmitir sus contenidos en línea, sino también ofrecer nuevas formas de interacción con los oyentes a través de las redes sociales, las comunidades de oyentes y las videocámaras para internet (Starky \& Weichselbaum, 2013). Por último, la llamada radio por internet o radio digital transforma la experiencia de acceso y demanda de programas en la medida en que los radioescuchas pueden escoger los contenidos y escucharlos en vivo o a través de podcasts. Todas estas características generan nuevos ambientes de escucha y por tanto, una relación ecológica diferente de la generada por la radio tradicional.

Son pocos los estudios que han abordado la radio según una mirada ecológica. En el interior del campo de la comunicación, la Escuela de Media Ecology (Kong, 2006) es la tradición que se ha enfocado en estudiar los medios de comunicación como tecnologías de pensamiento y como extensiones de la mente humana. Sin embargo, los estudios sobre la radio colombiana se han enfocado en examinar este medio como dispositivo de transformación social (Bonilla et al., 2011; Durán, 2011; El’Gazy, 2011; Mata, 2012) y no como tecnología del pensamiento. En América Latina se comienza a notar el interés en el estudio ecológico de la radio a partir del abordaje de temas como las aplicaciones para la radio por internet, la interactividad, las posibilidades ecológicas de accesibilidad de la radio, la simul- 
taneidady la mediatización del pensamiento narrativo (Balaguer, 2010; Cadavid y Moreno, 2013; Delgado, 2011; Díaz, 2000; Freire y Villar, 2010; García, 2010; Renó y Renó, 2015; Romeu y Piñón, 2014).

En el ámbito norteamericano, vale la pena resaltar dos artículos que presentan una mirada ecológica de la radio. En el primero, Soukup y Paul (2004) explican la naturaleza de la situación retórica que genera la radio a partir del uso de una voz que no ve ni es vista por los oyentes. En el segundo, Micheti (2005) aborda los procesos de transcodificación que lleva la radio consigo en la medida en que "la mente trata de compensar la falta de datos sensoriales a través de representaciones que son predominantemente visuales" (p. 245). Sin embargo, puede afirmarse que en redes y journals ${ }^{3}$ sobre media ecology o sobre radio ${ }^{4}$ es difícil encontrar estudios que examinen la radio según esta perspectiva ecológica.

Teniendo en cuenta este vacío en la literatura y considerando el importante papel que ha desempeñado la radio en Colombia y las transformaciones que ha enfrentado con la llegada de internet, este estudio analizala manera como el uso de dispositivos tecnológicos móviles ha transformado la forma de escuchar radio y cómo estas prácticas han llevado a la radio a generar nuevos ambientes de producción y escucha primordialmente apoyados en la oralidad terciaria. De esta manera, a través de un estudio fenomenológico basado en entrevistas, este artículoexamina la manera como la oralidad terciaria se constituye como tecnología de pensamiento que cambia la experiencia de escucha de la radio en plataformas web.

\section{Oralidades y escritura}

La radio supone la generación de un ambiente particular basado en la palabra y, específicamente, en la oralidad de la palabra, la cual opera como tecnología del pensamiento, que conlleva formas específicas de percibir e interpretar el mundo. De esta manera, puede afirmarse que la radio se basa en el lenguaje de la oralidad y, más concretamente, en las oralidades

3 En el journal Explorations in Media Ecology, por ejemplo, predomina el análisis ecológico de prácticas educativas o de otros medios de comunicación diferentes de la radio.

4 En journals especializados en la radio, como The Radio Journal o Journal of Radio and Audio Media, tampoco parecen prevalecer estudios ecológicos sobre la radio. 
secundarias y terciarias. Para entender lo que esto significa, podemos imaginar un espectro, cuyo extremo izquierdo representa la oralidad pura o primaria y cuyo extremo derecho representa la literalidad de la escritura. La oralidad pura hace referencia a la oralidad de las culturas que no tienen ni conocen la escritura. La literalidad, por su parte, corresponde a las culturas que conocen y usan la escritura como medio de comunicación. En puntos intermedios de este espectro, pueden ubicarse la oralidad secundaria y terciaria en la medida en que ambas comparten elementos tanto de la oralidad como de la literalidad.

En la oralidad, la naturaleza oral de la palabra supone un tipo particular de comunicación e interacción, en el cual la palabra más que un signo constituye un evento. De esta manera, la palaba oral no es solo la representación verbal de un referente, sino también un modo de acción. Para Ricoeur (1976), por ejemplo, la palabra hablada se presenta como un suceso en la medida en que invita a la participación y a la intersubjetividad con el otro. A diferencia de la palabra escrita, que generalmente se lee en silencio y a solas, la palabra oral se pronuncia en voz alta a un interlocutor, lo cual genera un proceso de comunicación interpersonal distinto de la escritura.

Para Ong (2002) y McLuhan (1964) la oralidad no debe ser reducida a la práctica física de hablar, sino que debe ser considerada como tecnología de pensamiento, forma de conciencia y estado de la mente. Como tecnologías, la oralidad y la escritura tienen dimensiones tanto interiores como exteriores: ambas funcionan como dispositivos externos, pero también operan como formas interiorizadas de conciencia, que influencian lo que se dice y el cómo se dice. En cuanto tecnología de pensamiento, la oralidad se presenta: 1) como pantalla terminológica a partir de la cual se percibe el mundo de una manera determinada (Burke, 1966).2) Como ventana a partir de la cual se observa la realidad de manera diferente de como se registra a través de la escritura (Altree y Ong, 1973). 3) Como tecnología que introduce una ecología particular de producción de significado (Dowd, 2014). Estas especificidades en la manera de percibir el entorno son distintas en la oralidad primaria, secundaria y terciaria, y serán abordadas en las secciones subsiguientes. 
Son conocidas las censuras que han recibido las ideas de McLuhan y Ong por parte de críticos que señalan en el pensamiento de estos autores una visión lineal de la historia y un determinismo tecnológico y comunicativo en la sociedad (Furniss, 2004; Scheunemann, 1996). A su vez, son también conocidas las respuestas y problematizaciones a estas críticas (Farrell y Soukup, 2002; Roncallo, 2009). Para este artículo bastaría añadir que, en primer lugar, hablar de distintas oralidades no implica una visión lineal según la cual unas superan a las otras y que la oralidad primaria, por ejemplo, es característica de sociedades "atrasadas", prelógicas o primitivas; en otras palabras: a las distintas oralidades no subyace un nivel de desarrollo social específico. En segundo lugar, la visión dicotómica de la díada oralidad-escritura de la que se acusa a Ong puede ser superada fácilmente al ubicar estas tecnologías de pensamiento en un continuo o espectro - como se señaló al comienzo de esta sección- en el cual estas se presentan en términos dialécticos y complementarios.

\section{Oralidad primaria}

Como se anotó, la oralidad pura es característica de aquellas culturas que no conocen la escritura y que han desarrollado patrones y estrategias de pensamiento que les permiten crear, mantener y reproducir el conocimiento. A estos patrones Ong (2002) los llama psicodinámicas de la oralidad y los usa para explicar por qué en las culturas primariamente orales las expresiones y los pensamientos son aditivos, agregativos, redundantes, conservadores, cercanos al mundo vital, de matiz agonístico, homeostáticos y situacionales. Comprender estas psicodinámicas es difícil para individuos - y en especial para académicos - que ya han interiorizado las formas de pensar de las culturas literalizadas.

Histórica y culturalmente, la oralidad primaria se transforma con la invención de la escritura. Sin embargo, esto no supone su desaparición, sino más bien su transformación en lo que se conoce como oralidad secundaria. Como claramente explica Ong (1971), las distintas tecnologías de pensamiento raramente aniquilan a sus predecesoras. El viejo miedo de Platón (2001), según el cual la escritura eliminaría la oralidad, ha sido negado por la historia, al mostrar que las nuevas tecnologías alteran, extienden o recuperan a las anteriores (Dowd, 2014). 


\section{Oralidad secundaria}

La oralidad secundaria es propia de sociedades que conocen y usan la escritura, pero que obviamente no prescinden de la oralidad para comunicarse. En la medida en que la oralidad es un dimensión fundamental de las prácticas comunicativas cotidianas, las sociedades orales no son menos orales que aquellas que no conocen la escritura (Furniss, 2004). Las diferencias radican en las formas de producción y reproducción del conocimiento, en la manera como el residuo oral se manifiesta en la cotidianidad (Ong, 1977) y en la mediación mecánica o electrónica que se da en este tipo de oralidad. La situación se hace mucho más compleja al considerar la aparición de los medios de comunicación en la medida en que estas tecnologías introducen nuevas formas de representación y narración. En cuanto el teléfono, el cine, la radio y la televisión, tienen un fuerte componente oral. Ong (2002) afirma que estos medios se soportan en la oralidad secundaria, la cual define como el lenguaje de los medios y las tecnologías que dan primacía a la oralidad, pero que están, de alguna manera, influenciados por la escritura.

Respecto del lenguaje, la oralidad secundaria se constituye como un sistema abierto que depende de la escritura y la imprenta (Durand, 1984; Ong, 1977). La anterior afirmación puede ser ejemplificada si imaginamos un locutor radial que oralmente presenta las noticias, pero que en realidad está leyendo en voz alta un libreto previamente escrito. Incluso si el locutor improvisa su mensaje y no se apoya en ningún tipo de libreto, su comunicación aún corresponde a la oralidad secundaria, pues su forma de pensar ya está moldeada por las psicodinámicas de la escritura. Es en este sentido que la oralidad secundaria es literalizada en distintos niveles según los tipos de interacciones. Además de estar influenciada por la escritura y de ser predominantemente mediada, la oralidad secundaria tiene un fuerte componente de participación,que se explica por la herencia oral de la vida comunal y el matiz agonísticoque se aviva con la presencia de las audiencias para el caso de los medios de comunicación.

No hay muchas investigaciones que profundicen en estas características de la oralidad secundaria o que la aborden enrelación específica conla radio (Scheunemann, 1996). Un estudio realizado a la radio informativa 
colombiana (Angel, 2014) concluye que, en la radio analógica o tradicional, la oralidad secundaria se manifiesta en tres niveles de comunicación: empático, gramatical y dialógico. El nivel empático incluye las funciones fática y prosódica del lenguaje con las cuales los radiohablantes establecen contacto y se relacionan con sus interlocutores a través del uso de interjecciones, ritmos y tonos de conversación. De acuerdo con el nivel gramatical, los radiohablantes expresan sus ideas mediante la puesta en práctica de reglas específicas relacionadas con el género, la enumeración, la redundancia, la espontaneidad y el flujo de información. Por último, el nivel dialógico se refiere a la forma en que los radiohablantes se involucran en distintos tipos de diálogos (paralelo, pedagógico, colaborativo y controversial) en el contexto de una situación retórica. Más allá de la descripción de este tipo de "psicodinámicas" de la oralidad secundaria de la radio, se hace necesario indagar sobre las características específicas de la radio producida y consumida en entornos digitales, la cual genera, tal como afirma Logan (2010), un tipo de oralidad distinta que él llama oralidad terciaria y que se abordará en la siguiente sección.

\section{Oralidad terciaria}

Las novedades narrativas y ecológicas que plantean los nuevos medios y plataformas de comunicación han llevado a acuñar el término oralidad terciaria para definir la oralidad propia de los medios digitales. En palabras de Logan (2010), este es el "territorio de la oralidad digital, es decir, la oralidad de los correos electrónicos, blogs, listas de servidores o mensajes de texto los cuales están mediados, paradójicamente, por los textos escritos transmitidos por internet" (p.103). La inclusión de este tercer tipo de oralidad muestra el complejo y enriquecido ambiente de producción y escucha de la radio digital, la cual incorpora diversas tecnologías de manera simultánea. Como expresa Logan (2010), un enfoque ecológico de los medios conecta estas diversas tecnologías y, más allá de ello, todos los aspectos comunicativos e informáticos propios de los medios de comunicación contemporáneos y estudia sus interacciones como parte de un ecosistema mayor de relaciones.

Dicha oralidad, que implica la anterior, supone un lenguaje narrativo con una lógica de producción diferente, que articula ficción y actualidad, 
información y entretenimiento. A su vez, refiere modos de narrar interactivos que incluyen prácticas ideográficas dinámicas (Piscitelli, 2002) y modos mediáticos de habitar el mundo. De esta manera, la oralidad terciaria subsume los diferentes canales de representación (icónico, simbólico y enáptico) para hacer una conjunción de tramas narrativas lógicas, interactivas y vivenciales que combinan imágenes, sonidos y tonos quinestésicos propios de la hipertextualidad de la radio digital. Precisamente, el objetivo del estudio que acá se presenta fue el de explorar ese ecosistema de relaciones, que supone la radio digital en el contexto de la oralidad terciaria en la que se enmarca.

\section{Metodología}

Como explica Anton (2014), la fenomenología es uno de los enfoques metodológicos más empleados para comprender la ecología de los medios. Aunque la mayoría de las veces se trata de enfoques diacrónicos que permiten analizar la manera como la introducción de una tecnología trae consigo transformaciones considerables a lo largo de un periodo histórico bastante amplio (por ejemplo el estudio de las transformaciones en la concepción del tiempo que trajo consigo la invención del reloj), también son frecuentes los abordajes sincrónicos que permiten examinar las experiencias de las audiencias en unidades de tiempo menos extensas (Chittenden, 2012; Dowd, 2014; Jubien, 2012). En términos generales, la fenomenología puede definirse no solo como una tradición filosófica, sino también como una metodología de investigación basada en el desvelamiento de las esencias a través de la descripción de experiencias, desde el punto de vista de los actores.

Se aborda el modelo de la fenomenología descriptiva de Schutz (1993) bajo el principio ontológico según el cual es a través de la interacción social que se experimenta la realidad, la cual se expresa en significados que, a la vez, dependen del potencial interactivo en un entorno particular. En esta medida, hay que reconocer, en el ejercicio investigativo, tres conceptos clave en Schutz: 1) El mundo de la vida como esa realidad experimentada a través de patrones de interpretación legitimados socialmente. 2)La intersubjetividad como una comunicación bidireccional a través de formas rutinarias de codificar la vivencia para comprenderla y, en consecuencia actuar. 
3)Las tipificaciones o códigos culturales compartidos. A partir de la fenomenología, se busca, entonces,acceder al marco de significación de un fenómeno particular a partir de la interpretación de las experiencias que ese fenómeno supone.

El recuperar los significados de la experiencia de escucha de radio a través de internet demanda una metodología fenomenológica, que, haciendo una adaptación de la propuesta fenomenológica de Martínez (1983, 2002), supone tres momentos: 1) descripción del significado en términos empíricos o de lo experimentado (eidético), 2) identificación del significado del significado en términos teóricos (noético) y 3 ) desvelamiento del sentido respecto de tendencias o tipificaciones (noemático).

Para este estudio, la comprensión de las experiencias de escucha de la radio digital y, puntualmente, de la ecología que supone este tipo de radio, se hizo a través del análisis de entrevistas realizadas a 20 radioescuchas de emisoras digitales (profesionales en ejercicio en las áreas de comunicación y periodismo, ingeniería, administración, contaduría, derecho, psicología y biología). Dicha unidad de trabajo se cerró mediante la técnica de saturación teórica. En un sentido similar al de Chittenden (2012) y Jubien (2012), se entrevistaron estos radioescuchas para conocer cómo las transformaciones de la radio cambian la experiencia de escucha por parte de sus audiencias y suponen un nuevo modo de relación con el medio. Las entrevistas se diseñaron según los cuatro temas fenomenológicos, existenciales enunciados propuestos por Van Manen (2007) y Jubien (2012):

- Espacialidad: lugares donde se escucha radio y dispositivos o plataformas a través de los cuales se escucha.

- Temporalidad: momentos en que se escucha radio y tipo de programas (en vivo, podcasts, etcétera).

- Corporalidad: manejo del cuerpo al escuchar radio (actividades que se realizan mientras se escucha, manejo de audífonos, posiciones de escucha, etcétera).

- Relacionalidad: relaciones que se entablan con otras personas al escuchar la radio (interacciones a través de las redes sociales, personas con quienes se escucha o se comparte lo que se escucha, etcétera). 
A continuación, se describe y analiza la experiencia de escucha de la radio digital para exponer tres posibles características de la oralidad terciaria de este tipo de radio.

\section{La experiencia de escucha de la radio digital}

En esta sección se describen las relaciones ecológicas de la radio digital respecto de los cuatro temas fenomenológicos expuestos en la sección anterior. De esta manera, las entrevistas realizadas a los radioescuchas digitales se estructuraron desde el punto de vista de la temporalidad, espacialidad, corporalidad y relacionalidad que supone para ellos la radio digital. Siguiendo los principios metodológicos propios de la fenomenología, cada entrevista se concibió como el relato de la experiencia de consumo radial, cuyo análisis supuso las tres etapas mencionadas: 1) la descripción del significado de escucha de radio digital, 2) la interpretación-en un nivel noético- de esa experiencia de escucha y 3 ) la propuesta de diez tendencias o tipificaciones de las temporalidades, territorialidades, corporalidades y relacionalidades de la radio digital, las cuales se describen a continuación. A partir de esta descripción, se reflexionará en torno a la oralidad terciaria de este tipo de radio.

\section{Espacialidad: territorios expandidos}

La invención del computador personal y de internet modificó considerablemente la manera como se accede a los medios de comunicación. En la radio supuso la introducción del computador como soporte de acceso a los contenidos radiales diferente del aparato radial, la grabadora, incluso el transistor. Como tecnología, cada uno de estos dispositivos genera un ambiente de escucha diferente. Ubicado en el centro de la sala, el aparato radial, por ejemplo, invitaba a la familia a escuchar programas y radionovelas en familia. En tiempos de racionamiento eléctrico, como los vividos en el territorio colombiano durante 1992, la radio sirvió como compañía a ciudadanos que regresaban temprano a sus casas o a aquellos que permanecían, a oscuras, en sus lugares de trabajo.

La llegada de internet, por su parte, también hageneradonuevos ambientes de escucha de la radio basados en dispositivos, como el compu- 
tador, los teléfonos inteligentes y las tabletas. Al igual que sucede con el radiotransistor, el teléfono inteligente permite "llevar la radio" a cualquier lugar. Sin embargo, a diferencia del radio convencional, la conectividad a internet permite acceder a emisoras de cualquier lugar del mundo desde teléfonos y computadores. Las experiencias relatadas en las entrevistas permiten identificar cuatro ambientes de escucha establecidos a partir de los lugares y dispositivos utilizados para el consumo de radio:

1) Los territorios eidéticos mediante los cuales la radio, en su uso digital, implica un instrumento informativo similar al fenómeno zapeo que permite a los oyentes realizar paneo de datos para mantenerse actualizados. Los siguientes fragmentos de dos de los entrevistados ilustran este tipo de territorio: "Converso sobre lo escuchado en la radio cuando el tema se presta para hacer un comentario" y " [con la radio] se vive mejor el tiempo y el espacio, pues se sabe qué pasa en ese momento en otras partes”. De esta manera, la radio digital facilita el incremento del acervo informacional en la medida en que hace posible acceder a múltiples escenarios informacionales de distintos espacios geográficos.

2) Territorios expresivos que operan como facilitadores de la comunicación emocional en la medida en que propician la interacción con otros, lo cual, para Scolari (2008), se asocia al fenómeno de las redes sociales como plataformas de la acción dialógica interactiva de una cibercultura que facilita a los oyentes sentirse ciudadanos del mundo y ampliar la red interactiva como un posible territorio de encuentro. Los entrevistados describen estos espacios de expresión que amplifica la radio digital respecto de las posibilidades que tiene este tipo de radio de "llevar el mundo en la mano y en los oídos” y de "aproximarse a nuevos lugares a través del sonido, la música y los locutores de otras emisoras que comúnmente no escucho en los espacios radiales de mi ciudad”. Estos territorios expresivos también hacen que la radio genere posibles espacios de encuentro en cuanto amplían la red interactiva y extienden el espacio local, tal como manifiesta uno de los entrevistados: "[La radio digital] es una manera de acercarme a otros lugares, de escuchar otras dinámicas para hacer radio u oír y participar con contenidos diferentes de los que se difunden en mi ciudad". 
3) Territorios pedagógicos que funcionan como articuladores de experiencias educativas, cuyo objeto es el aprendizaje como posibilidad de acceso a la cotidianidad para facilitarla y cualificarla. Siguiendo a Postman (1999) (citado por Scolari, 2008), este uso educativo de la radio puede ser leído como una pedagogización de la experiencia del radioescucha digital que transciende el uso instrumental de la máquina para hacerla parte interactiva del ambiente. Según algunas respuestas de los entrevistados, esto se expresa en dos tipos de aprendizaje: a) aprender simultáneamente lo cotidiano desde la radio digitalcuando se afirma que, por ejemplo, "[aprendo de forma práctica porque el computador]me permite hacerlo a la par con otras actividades", y b) aprender lo actual mediante el uso de la radio digital como un demarcador de territorios sociales interactivos: "A mí me gusta escuchar lo que está pasando en este momento, ¿para qué escuchar lo que ya pasó? Me gusta el calor del momento y las reacciones. De lo contrario, leo las noticias y los análisis. Nunca descargo un programa porque siento que ya está obsoleto y no me dice lo que está pasando ya”.

4) Territorios desplazados que reflejan la manera en que la radio, al igual que otros medios, permite a los oyentes,mediante el acceso digital, abrirse a narrativas múltiples; es decir, no solo darle un uso literal (escuchar radio, particularmente noticias), sino un uso complementario como narrativa de trasfondo o ambientación cuando se realiza otra tarea. Los radioescuchas entrevistados para este estudio relatan la manera en que su computador no es solo su principal herramienta de trabajo, sino su dispositivo de acceso a la radio que no solo hace que la radio "entre a la oficina", sino que también brinde compañía de fondo mientras se realizan diversas tareas. Para una de las entrevistadas, por ejemplo, poder escuchar radio en la oficina "hace que me sienta como si estuviera en casa"; para otro, "es un medio fácil de enterarse de las últimas noticias o acontecimientos mientras uno se dedica a las labores cotidianas, como el trabajo". Así, la radio no demarca un territorio particular de uso porque ella misma configura un territorio en el que conviven otros múltiples territorios.

\section{Temporalidad: trechos alternos}

En la década de 1950, la radio fue usada como reloj por habitantes de ciudades colombianas cansados de mirar la hora equivocada en relojes 
públicos mal sincronizados de iglesias y grandes construcciones. De esta manera, los radiotransistores permitían a estos habitantes escuchar la hora, frecuentemente repetida en los programas radiales, mientras se desplazaban de un lugar a otro. Sin embargo, la temporalidad de escucha de la radio también se ha modificado con las transformaciones de los dispositivos tecnológicos. No solo han cambiado los usos temporales de la radio, sino también los momentos en que se escucha este medio. Así, la rutina de escuchar la radio en tempranas horas de mañana y de camino al trabajo descrita por Lalinde (1998) ha cambiado con el uso de dispositivos móviles, que permiten escucharla en distintos momentos del día. Aunque esta práctica fue primero introducida por el radiotransistor, se ha intensificado con el computador en la medida en que esta es la herramienta de trabajo de muchos empleados que pueden, a través de una misma herramienta y de manera simultánea, cumplir con sus responsabilidades labores y escuchar radio.

Por otro lado, la radio por internet transforma significativamente el carácter temporal-simultáneo de la radio en cuanto permite su escucha a través de archivos con audios previamente grabados. En este sentido, las descargas de podcasts cambian la relación simultánea de producción y recepción de la radio, pues permiten a los oyentes escuchar programas en momentos distintos de los que fueron producidos. Sorprendentemente, esta posibilidad no es aún ampliamente acogida por los radioescuchas entrevistados, quienes consideran que la radio en vivo los actualiza y los convoca mucho más que la radio "en frío". Este rechazo se ilustra en el relato de una de las entrevistadas: "A mí me gusta escuchar lo que está pasando en este momento, ¿para qué escuchar lo que ya pasó? Me gusta el calor del momento y las reacciones. De lo contrario, leo las noticias y los análisis. Nunca descargo un programa porque siento que ya está obsoleto y no me dice lo que está pasando ya”. Así, el análisis de las entrevistas muestra la percepción de la multitemporalidad a la que acceden los radioescuchas contemporáneos. Este tema de la temporalidad, aunque está muy ligado a la espacialidad, rompe con gramáticas lineales para acercarse a la generatividad sincrónica de las formas de covivir el tiempo. Tiempo que se percibe en una doble perspectiva: dinamicidad y simultaneidad así: 
1. Temporalidad dinámica con una radio activa que se adapta a las rutinas de los oyentes y les permite conectarse con un mundo complejo y hacer una conjunción del ciberespacio con el socioespacio. Este tipo de temporalidad se ilustra en la opinión de gran parte de los entrevistados, quienes coinciden en plantear que la radio se va "acomodando a sus horarios" en cuanto les permite desempeñarse en temporalidades simultáneas en las que, por ejemplo, pueden "hacer otras actividades, como el deporte y estar informado" o "trabajar e irme enterando de cosas”. Se asume así un tiempo no lineal que tiene que ver con los usos de la radio que se acomodan a las propias rutinas y con la vivencia de la cotidianidad desde la multiplicidad territorial.

2. Temporalidad simultánea a través de las posibilidades que ofrece la radio digital de trasladarse en el tiempo con la viabilidad de incrementar una memoria narrativa permanente. Esta simultaneidad temporal actúa como un radar virtual para identificar e identificarse con distintos momentos de la experiencia temporal. Este territorio se expresa en dos tipos de percepciones de los entrevistados. Por un lado, como vivencia de lo cotidiano desde la multiplicidad territorial, sobre lo cual uno de los entrevistados afirma que: "Me parece cómodo escuchar [la radio] y estar al tanto de las noticias del día, mientras desayuno y mientras voy en el carro en la congestión de la noche”. La segunda percepción tiene que ver con la radio digital como medio facilitador de la transtemporalidad, como se ilustra en el siguiente fragmento: "[Con la radio] se vive mejor el tiempo porque se puede saber qué pasa en ese momento en otras partes".

\section{Corporalidad: simbiosis quinestésica}

La radio siempre ha permitido la realización de otras actividades simultáneas a la escucha. Al igual que el aparato radial y el radiotransistor, los nuevos dispositivos tecnológicos permiten realizar tareas domésticas, hacer deporte, desplazarse a otros lugares y trabajar mientras se escucha. Incluso el uso de audífonos que supone una extensión del oído a través de un dispositivo tecnológico particular que ya había sido introducido por el radiotransistor. 
La vivencia de la radio digital es la de conexión con el mundo a través delas sensaciones, emociones y percepciones corporales. Constituye la vivencia de una corporalidad modeladora de la propia vivencia, que adquiere su potencial por la ayuda del dispositivo móvil. El cuerpo se conecta desde todas sus dimensiones vitales para transitar lo cotidiano de manera más cercana a la propia experiencia y formas de actuar en el mundo. Se experimenta una quinestesia emocional en la que se reconoce el esquema corporal en equilibrio. Al igual que en otros medios, la radio activa el tono emocional, pero, gracias a su acceso por medios digitales, permite conectarse con otras experiencias vitales en forma interactiva. Se observan, entonces, dos mediaciones en la dinámica de la corporalidad:

1. Ambientación activa, que hace de la radio un instrumento para crear un ambiente cognitivo modelador de sensaciones, motivaciones y cogniciones que afectan la percepción del espacio vital cotidiano. Este modelamiento se manifiesta en dos tipos de percepciones por parte de los entrevistados: en primer lugar, por la activación de la esfera afectiva mediante un tipo de comunicación ritualizada que se manifiesta en ideas, como "[escuchando la radio] me siento como si estuviera en casa”. En segundo lugar, esta ambientación activa se refleja en la sensación de encuentro con otros: "[La radio] te permite no sentirte solo; la voz de la radio se transforma en una presencia ausencia que acompaña o que incluso llena un vacío".

2. Consumo psicológico o percepción intuitiva de la radio, primero, como soporte emocional con cualidades anímicas sinérgicas, en la medida en que la mayoría de los oyentes la perciben como un compañero de camino que les permite generar un espacio psicológico equilibrado; $y$, segundo, como soporte social o espacio recreativo que se expresa en las posibilidades de la radio, como un referente técnico, para propiciar las relaciones interpersonales. Según las experiencias compartidas por los entrevistados, la radio permite a los oyentes mitigar el silencio y la soledad, y hacer catarsis (corporal/emocional) de sus propios sentimientos a través de la identificación con los contenidos que escuchan: "Muchas veces siento risa y a veces rabia por los comentarios o las noticias que dan" o "Escuchar radio me relaja y me 
pone al orden del día”. Así, la radio puede, por ejemplo, crear entornos cognitivos cotidianos relajantes.

\section{Relacionalidad: interactividad creciente}

La mayor transformación ecológica que trae consigo la radio digital tiene que ver con el modo de relacionalidad que ofrece, el cual se materializa en las diversas formas de participación e interacción que tienen las audiencias entre sí y con los realizadores de los programas radiales. De esta manera, las redes sociales, como Twitter y Facebook, y las plataformas propias de participación de las emisoras (blogs, chats propios, centros de mensajes) extienden la participación que en la radio tradicional consistía en llamadas telefónicas al aire o cartas a los productores. Estas nuevas posibilidades de participación hacen que el oyente viva una experiencia no solo de escucha, sino de interacción con otros oyentes o con los realizadores de los programas. Más aún, cuando se publican en redes sociales, estas interacciones y comentarios son masificados, con lo que el oyente deja de ser un receptor pasivo y pasa a ser productor de información o, por lo menos, productor de reacciones y opiniones sobre la información que recibe.

Según los entrevistados, las interacciones con las emisoras o con las redes sociales les permiten cuatro tipos de participaciones: 1) manifestar su opinión frente a los temas que escuchan, 2) agregar información nueva sobre esos temas, 3 ) resaltar algún subtema o elemento particular con relación a lo que escuchan y 4) analizar la información recibida según su propia experticia. La posibilidad de sentirse acompañado que la radio ha ofrecido desde su surgimiento se extiende con la radio digital en cuanto esa compañía ya no consiste solo en la posibilidad de escuchar a otro cercano, sino en entablar en un diálogo con él, con otros que lo escuchan o con otros completamente ausentes de esta interacción comunicativa. Estas posibilidades que trae consigo la radio digital muestran una relacionalidad simbiótica que refleja la necesidad de los oyentes de ampliar sus marcos de actuación social. Para ello, la experiencia radial digital muestra una doble connotación: contribuye al ambiente ecológico de recepción como herramienta emocional y posibilita el uso simultáneo interactivo de medios. Más allá de los 
tipos de interacciones descritos, el análisis de las experiencias compartidas por los entrevistados muestra dos tipos de vivencias significativas:

1. Informarse para socializar, que hace que los oyentes perciban la experiencia radial digital como un medio de integración social. De esta manera, escuchar radio en forma interactiva permite a los oyentes sentirse integrados al mundo y conectados con lo global para reconocerse como parte de un entorno multimedia. Esta simbiosis lleva a referenciar la experiencia radial digital desde dos alcances: por una parte, activar referentes para la interacción cotidiana, lo cual se manifiesta en el énfasis hecho por los entrevistados sobre la manera como la radio los invita a hablar con su familia, compañeros de trabajo o amigos sobre los contenidos que a través de ella escuchan. Por otro lado, la radio permite hacer contacto con el mundo cotidiano en la medida en que hace que los oyentes estén informados sobre el acontecer local, regional, nacional o mundial, en la medida en que perciben la radio digital como una posibilidad para estar actualizado y poder "opinar en casa, [es decir], socializar".

2. La comunicación afectiva, que hace que la radio, al activar un ambiente quinestésico, permita a los oyentes prepararse psicológicamente para sus interacciones con otros. En este sentido, permite que la comunicación humana trascienda su función instrumental y referencial a una comunicación basada en el diálogo generativo mediante el intercambio de mensajes que personalizan y forjan aprendizajes. Para los entrevistados, este tipo de vivencia se expresa por la percepción de un diálogo de compensación psicológica y competencia técnico-comunicativa: "Para mí es un modo de sentirme conectada con el mundo, de que la información llegue de diferentes lugares y pueda interactuar con facilidad”, "[La radio digital] es para mí compañía, con facilidad y libertad de manejo”.

Como puede verse, estas diez tipificaciones de las temporalidades, territorialidades, corporalidades y relacionalidades de la radio digital se superponen en la experiencia de escucha radial, por lo que su separación y delimitación solo es posible con fines analíticos de descripción y clasificación. Por ejemplo: la simultaneidad entre el consumo de radio y la realización de 
otras actividades puede explicarse respecto de territorialidades, temporalidades, corporalidades y relacionalidades. Lo que varía, en cada caso, es la manera como se presenta y analiza esta condición de simultaneidad, bien sea respecto de lugares, momentos, sensaciones o interacciones. Por último, es evidente que esta condición de simultaneidad y otras descritas por los entrevistados no son propias de la radio digital, sino que se trata de ambientes ya propiciados por la radio tradicional, pero que han sido expandidos con la radio digital. De esta manera, al aplicar el análisis mcluhiano de tétradas (Dowd, 2014) a las experiencias de escucha previamente presentadas, puede verse cómo la radio digital extiende los ambientes y las posibilidades que ya había traído consigo la radio tradicional en lugar de revertirlos, reversarlos o hacerlos obsoletos.

Así, la experiencia de escucha de la radio digital, caracterizada por activar vivencias quinestésicas, facilitar la simultaneidad en la elaboración de tareas y facilitar el acceso a contenidos, produce una experiencia ciberestética caracterizada por la percepción de sentimientos equilibradores de los estados vitales en las interacciones cotidianas; es decir, la radio como medio digitalizado genera un proceso resocializador intrínseco para su proyección extrínseca en la interacción cotidiana. Dicha experiencia muestra, como trasfondo, territorios geográficos y sociales, propios de las redes, y la participación virtual se constituye como herramienta potencial de apoyo ecológico, en el sentido de mediar, a través de la voz y la emoción, las funciones de informar, formar, socializar y entretener propias de los medios de comunicación. Al ser producto de una fusión de medios, la radio digital permite combinar lo instrumental (oír, manipular), lo superficial (reconocer objetos), lo conversacional (generar diálogo no solo inter- sino intrapersonal) y lo espacial (propiciar intercambios con otros) en el espacio vital de la actualidad cotidiana que sobrepasa las dimensiones de la red.

\section{Apuntes finales sobre la oralidad terciaria de la radio digital}

A manera de discusión, el análisis de la temporalidad, espacialidad, corporalidad y relacionalidad de la radio digital permite inferir, a partir de los hallazgos, algunas características iniciales de la oralidad terciaria, en la que se 
sustenta este tipo de radio. Estas características tienen que ver con la vivacidad, la transcodificación y la adresividad de la radio digital, las cuales se explican a continuación.

El análisis previamente presentado sobre la temporalidad de escucha de la radio configura, en gran parte, la vivacidad como una primera característica de la oralidad terciaria en la radio digital. La simultaneidad entre su producción y la recepción hacen de la radio un medio bastante espontáneo (Tolson, 2006). Con la radio digital, esta espontaneidad se modifica en el sentido en que no siempre el acto de recepción es simultáneo, pues los oyentes tienen oportunidades de acceder a podcasts que les permiten escuchar programas previamente emitidos. Los entrevistados relatan la manera como esta nueva radio altera las rutinas de escucha y modifica las relaciones temporales tradicionales. La radio digital también permite cambiar la condición efímera del sonido en cuanto se puede pausar y retroceder audios ya digitalizados con ayuda de aplicaciones y dispositivos tecnológicos.

Sin embargo, esta condición de acceso y escucha de la radio no genera transformaciones estructurales en el lenguaje de la radio que afecten su espontaneidad. En otras palabras, independientemente de que los programas se escuchen o no en vivo, la espontaneidad se mantiene como una característica de los géneros radiales, los cuales se definen respecto de las expectativas que tienen los oyentes con relación a la estructura, tipos de discurso y tipos de relaciones que un mensaje entabla con sus audiencias (Bakhtin, 1999; 2001; Furniss, 2004), lo cual no significa que la oralidad terciaria constituya un género en sí mismo, pues existen muchos géneros radiales; esta situación implica que la vivacidad de la radio digital la lleva a emplear géneros cercanos a los de la comunicación cotidiana, que reproducen las características de una conversación con matiz agonístico y tonos participativos. De esta manera, aunque la espontaneidad resalta el carácter efímero de la oralidad, también constituye una expectativa de escucha, según la cual los oyentes esperan escuchar locutores y personajes que hablen un lenguaje cercano y que los inviten a interactuar a través de distintos soportes. 
Por su parte, la corporalidad y la espacialidad en el consumo de radio materializan una segunda característica de la oralidad terciaria, como es la transcodificación, la cual puede definirse como la sustitución de un conjunto de códigos por otro (Micheti, 2005, p. 148). Así, los estímulos táctiles, visuales y olfativos son transcodificados en la radio en sonidos, música y lenguaje verbal. La radio invita a los oyentes a transformar signos indexicales y abstractos en imágenes icónicas a través de presentaciones mentales. La radio digital extiende mucho más esta transcodificación no solo en la medida en que ofrece una interfaz de operación que no se tiene con la radio tradicional, sino porque, en ocasiones, ofrece imágenes y palabras escritas a través de esas interfaces.

Como se explicó en la sección anterior, estas interfaces que añaden los nuevos dispositivos tecnológicos cambian la corporalidad en la recepción en la medida en que permiten, por ejemplo, que un mismo dispositivo sea herramienta de trabajo y equipo de radio. Estas interfaces también modifican la espacialidad en la medida en que no se restringe el acceso y no solo se escuchan las emisoras del lugar donde se está, sino producciones y emisiones desde cualquier lugar del mundo.

Las experiencias de relacionalidad descritas en la sección anterior permiten, a manera de inferencia, explicar la tercera característica de la oralidad terciaria de la radio, la cual se llamará adresividad. Esta característica hace referencia a la condición de la voz en la radio no solo de transmitir significados y conectar individuos, sino de crear un evento comunicativo retórico y de invitar a la interacción. Esta adresividad está relacionada con la corporalidad y con las ya mencionadas posibilidades de participación e interacción que trae la radio digital.

De esta manera, como síntesis conclusiva,el análisis sobre la temporalidad, espacialidad, corporalidad y relacionalidad de la radio permiten identificar tres elementos de la oralidad terciaria de la radio digital. Evidentemente, es necesario realizar muchos más estudios que permitan profundizar las características de estos elementos y que hagan posible la identificación de nuevas psicodinámicas a partir de las cuales pueda tenerse una mejor 
comprensión de la ecología que supone la radio digital. No obstante, en una correlación directa con los existenciales fenomenológicos, los elementos de vivacidad, transcodificación y adresividad permiten inferir la presencia de un lenguaje narrativo polifónico que, siguiendo a Bakhtin (1999), evidencia múltiples registros, voces y puntos de vista en la experiencia de los escuchas de la radio digital. Esta presencia, a su vez, está caracterizada por su interactividad, ideografía dinámica y conjunción de canales auditivos, visuales y quinestésicos y constituye también una condición que deja ver el acoplamiento a otras formas de vivir la experiencia cotidiana. Igualmente, se podría afirmar que la oralidad terciaria existe siempre y cuando los mediadores culturales (en este caso los medios digitales) faciliten el acceso a ampliar la vivencia a escenarios de crecimiento comunicativo, en los cuales lo simultáneo, lo simbiótico, lo expandido y lo interactivo se combinan con la tecnología analógica para conjugar la ficción con la realidad y el entretenimiento con la ficción.

\section{Referencias}

Altree, W. y Ong, W. J. (1973). Why talk?: A conversation about language with Walter J. Ong. Chandler y Sharp Publishers.

Ángel,A. (2014). Radio and secondary orality: a rhetorical analysis of the Colombian radio programme "Hora 20". The Radio Journal, 12, 55-72.

Anton, C. (2014). Diachronic phenomenology: a methodological thread within media ecology. Explorations in Media Ecology, 13(1), 9-36.

Bakhtin, M.M. (1999). Estética de la creación verbal. Madrid: Siglo XXI.

Bakhtin, M.M. (1981). The dialogic imagination: four essays. Austin: University of Texas Press.

Bakhtin, M.M.(2001). The problem of speech genres. EnP.Bizzelly B.Herzberg (eds.), The rhetorical tradition: readings from classical times to the present (pp. 1226-1245). Boston: Bedford/St. Martin's. 
BalaguerPrestes, R. (2010). Zapping, navegación, nomadismo y cultura digital.Razón y Palabra,15(73). Recuperado el 12 de marzo de 2015 de http://www.redalyc.org/pdf/1995/199514908012.pdf

Bonilla, J.I., Restrepo, A., Vásquez, K. y Betancur, J.G. (2011). Cinco estudios de caso sobre buenas prácticas para superar el conflicto armado en Antioquia: claves, lecciones y balances. En J. M. Pereira y A.Cadavid (eds.), Comunicación, desarrollo y cambio social(pp. 241286). Bogotá: Editorial Pontificia Universidad Javeriana.

Burke, K. (1966). Language as symbolic action. California: University of California Press.

Cadavid Bringe, A.y Moreno Martínez, Ó. (2013). Evaluación cualitativa de radio audiencias por la paz en el Magdalena Medio colombiano. Signo y Pensamiento, 28(54), 276-299. Recuperado el 12 de marzo de 2015 de http://revistas.javeriana.edu.co/index.php/signoypensamiento/article/view/4538/3500

Castellanos, N. (2012). La radio colombiana, una historia de amor y de olvido. Signo y Pensamiento, 20(39), 15-23.

Centro Virtual de Noticias de la Educación (2013, 14 de febrero). 8 de cada 10 colombianos están usando internet. Recuperado el 17 de marzo de 2015 de http: / /www.mineducacion.gov.co/cvn/1665/w3article-318371.html

Chittenden, T. (2014). Remote Control? The shaping of communities of tennis spectators through the BBC's large TV screen coverage of wimbledon. Explorations in Media Ecology, 13(1), 49-66.

Delgado, E. (2011). La ecología de medios: unaetiqueta que marcó el antes y el después de las visiones macluhianas. En C. Arcila y A. Ferrer (eds.). Reflexionessobrecomunicación, tecnología y sociedad: 
digitalización y ecología de medios (pp.51-56). Bogotá: Universidad de los Andes.

Díaz Rascón, D. R. (2000). Mediática e información digital en México: el medio digital frente a los periódicos impresos, la radio y la televisión. Revista Latina de Comunicación Social, 31. Recuperado el 17 de marzo de 2015 de http://www.ull.es/publicaciones/latina/ aa2000kjl/z31jl/82david.htm

Dowd, J. (2014). A media ecological analysis of do-it-yourself education: Exploring relationships between the symbolic and the material realms of human action. Explorations in Media Ecology, 13(2), 155-175.

Durán, O.R. (2011). Los colectivos de comunicaciónciudadana en el Magdalena Medio. En J. M. Pereira yA.Cadavid (eds.), Comunicación, desarrollo y cambio social(pp.313-325). Bogotá: Editorial Pontificia Universidad Javeriana.

Durand, A. (1984). The concept of secondary orality: Observation about speaking and text in modern communications media. The Dalhousie Review, 64, 332-353.

El'Gazi, J. (2011). La experiencia de las emisoras ciudadanas y comunitarias o cómo hablar de cara al futuro más allá del conflicto armado. En J. M. Pereiray A.Cadavid (eds.), Comunicación, desarrollo y cambio social(pp. 299-311). Bogotá: Editorial Pontificia Universidad Javeriana.

Farrell, T. y Soukup, P. (eds.)(2002). An ong reader. Cresskill, NJ: Hampton Press.

Freire, J. y Villar Onrubia, D. (2010). Prácticas cartográficas cotidianas en la cultura digital. Razón y Palabra, 73. Recuperado el 4 de abril de 2015 de http://www.razonypalabra.org.mx/N/N73/ MonotematicoN73/01-M73Freire-Villar.pdf 
Fried Schnitman, D. (2008). El nuevo paradigma estético. Barcelona: Paidós.

Furniss, G. (2004). Orality: The power of the spoken word. NuevaYork: Palgrave MacMillan.

García, M. (2010). De giros y (sus) re(la)tos: fragmentos y disgresiones. Razón y Palabra, 73. Recuperado el 4 de abril de 2015 de http:// old.razonypalabra.org.mx/N/N73/Varia73/03Garcia_V73.pdf

Jubien, P. (2012). A phenomenology of the podcast lecture. Explorations in Media Ecology, 11(1), 73-85.

Kong Lum, C. M.(ed.) (2006). Perspectives on culture, technology and communication: The media ecology tradition. Cresskill, NJ: Hampton Press.

Lalinde Posada, A. M. (1998). Radio informativa: ¿es posible la participación? Signo y Pensamiento, 17(33), 47-58.

Logan, R. K. (2010). Understanding new media: extending Marshall McLuhan. Nueva York: Peter Lang.

Mapa de Medios (2015). La radio que oímos: balance 2012-2013. Recuperado el 19 de abril de 2015 de http:/ / www.mediosencolombia. com/la-radio-que-oimos/

Martínez Miguélez, M. (1983). Una metodología fenomenológica para la investigación psicológica y educativa. Anthropos, 6, 110-134.

Martínez Miguélez, M.(2002). La nueva ciencia: su desafío, lógica y método. México: Trillas.

Mata, M. C. (2012). Saber sobre la radio. Signo y Pensamiento, 17(33), 91-98.

McLuhan, M. (1964). Understanding media: the extensions of man. CA: Ginglo Press. 
Micheti, A. (2005). Images for the inner eye: the use of visually evocative techniques in radio. Explorations in Media Ecology, 4(3-4), 243-258.

Ong, W. (1971). Rhetoric, romance, and technology: Studies in the interaction of expression and culture. Ithaca: Cornell University Press.

Ong, W. J. (1977). Interfaces of the word: studies in the evolution of consciousness and culture. Ithaca, NY: Cornell University Press.

Ong, W.J. (1978). Literacy and orality in our time. En T. Farrell y P. Soukup (eds.), An Ong reader (pp. 465-477). Cresskill, NJ: Hampton Press.

Ong, W. J.(2002). Orality and literacy: The technologizing of the word. Nueva York: Routledge.

Ong, W. J. (2012). Rhetoric, romance, and technology: Studies in the interaction of expression and culture. Ithaca, NY:Cornell University Press.

Piscitelli, A. (2002). Cibercultura 2.0 (En la era de las máquinasinteligentes). Buenos Aires: Paidós.

Plato. (2001). Phaedrus. In P. Bizzel, \& B. Herzberg (Eds.), The rhetorical tradition: Readings from classical times to the present (pp. 138-168). Boston: Bedford/St. Martin's.

Renó, D. y Renó Brasil, L. (2015). Mapas interactivos como plataformas informativas para ciudadanos desconectados. Razón y Palabra, 19(89). Recuperado el 29 de abril de 2015 de http:/ / razonypalabra.org.mx/N/N89/M89/05_RenoReno_M89.pdf

Ricoeur, P. (1976). Interpretation theory: Discourse and the surplus of meaning. Texas: Texas Christian University Press.

Romeu, V. y Piñon, M. (2014). La ecologíacomunicativacomo germen de la comunicaciónestretégica. Razón y Palabra, 86. Recuperado el 
29 de abril de 2015 de http://ww35.razonypalabra.org.mx/N/ N86/V86/14_RomeuPinon_V86.pdf

Roncallo, S. (2009). Marshall McLuhan: la posibilidad de re-leer su noción de medio. Signo y Pensamiento, 54, 362-368.

Scheunemann, D. (1996). "Collecting shells" in the age of technological reproduction: on storytelling, writing and the film. En D. Scheunemann (ed.), Orality, literacy and modern media (pp. 79-94). Columbia: Camden House.

Schutz, A. (1993). La construcción significativa del mundo social. Barcelona: Paidós.

Scolari, C. (2008). Hipermediaciones: elementos para una teoría de la comunicación digital interactiva. Barcelona: Gedisa.

Soukup, S. J. y Paul, A. (2004). Voice, electronic media, and belief: some reflections on Walter Ong's perspective on the electronically mediated word. Explorations in Media Ecology, 3(1), 7-15.

Stark, B. y Weichselbaum, P. (2013). What attracts listeners to Web radio? A case study from Germany. Radio Journal: International Studies in Broadcast y Audio Media, 11(2), 185-20.

Tolson, A. (2006). Media talk: spoken discourse on television and radio. Edinburgh: Edinburgh University Press.

Van Manen, M. (2007). Phenomenology of practice. Phenomenology and Practice, 1, 11-30. 